\title{
Sequencing and analysis of the internal transcribed spacers (ITSs) and coding regions in the EcoR I fragment of the ribosomal DNA of the Japanese pond frog Rana nigromaculata
}

\author{
Masayuki Sumida*, Yoji Kato and Atsushi Kurabayashi \\ Institute for Amphibian Biology, Graduate School of Science, Hiroshima University, \\ Higashihiroshima 739-8526, Japan
}

(Received 22 July 2003, accepted 30 March 2004)

\begin{abstract}
The rDNA of eukaryotic organisms is transcribed as the 40S-45S rRNA precursor, and this precursor contains the following segments: 5' - ETS - 18S rRNA - ITS $1-5.8 \mathrm{~S}$ rRNA - ITS $2-28 \mathrm{~S}$ rRNA -3 '. In amphibians, the nucleotide sequences of the rRNA precursor have been completely determined in only two species of Xenopus. In the other amphibian species investigated so far, only the short nucleotide sequences of some rDNA fragments have been reported. We obtained a genomic clone containing the rDNA precursor from the Japanese pond frog Rana nigromaculata and analyzed its nucleotide sequence. The cloned genomic fragment was 4,806 bp long and included the 3'-terminus of 18S rRNA, ITS 1, 5.8S rRNA, ITS 2, and a long portion of $28 \mathrm{~S}$ rRNA. A comparison of nucleotide sequences among Rana, the two species of Xenopus, and human revealed the following: (1) The 3'-terminus of $18 \mathrm{~S}$ rRNA and the complete 5.8S rRNA were highly conserved among these four taxa. (2) The regions corresponding to the stem and loop of the secondary structure in 28S rRNA were conserved between Xenopus and Rana, but the rate of substitutions in the loop was higher than that in the stem. Many of the human loop regions had large insertions not seen in amphibians. (3) Two ITS regions had highly diverged sequences that made it difficult to compare the sequences not only between human and frogs, but also between Xenopus and Rana. (4) The short tracts in the ITS regions were strictly conserved between the two Xenopus species, and there was a corresponding sequence for Rana. Our data on the nucleotide sequence of the rRNA precursor from the Japanese pond frog Rana nigromaculata were used to examine the potential usefulness of the rRNA genes and ITS regions for evolutionary studies on frogs, because the rRNA precursor contains both highly conserved regions and rapidly evolving regions.
\end{abstract}

Key words: ITS, Japanese pond frog, Rana nigromaculata, ribosomal rRNA genes

\section{INTRODUCTION}

The ribosomal DNA (rDNA) found in the nuclear genome of eukaryotes is transcribed as the $40 \mathrm{~S}-45 \mathrm{~S}$ rRNA precursor and consists of tandemly repeated copies. The rRNA precursor contains the segments $5^{\prime}-$ ETS $-18 \mathrm{~S}$ rRNA - ITS 1 - 5.8S rRNA - ITS 2 - 28S rRNA - 3', where ETS and ITS are external and internal transcribed spacers that are removed during RNA processing (Gerbi,

Edited by Yoko Satta

* Corresponding author. E-mail: msumida@hiroshima-u.ac.jp
1986). The length of the rDNA unit varies greatly between different species, ranging from $6.8 \mathrm{kbp}$ in the protozoa (Lipps and Steinbruck, 1982) to $44 \mathrm{kbp}$ in the rat (Stumph et al., 1979). This variability in length can be accounted for by differences in a so-called non-transcribed spacer (NTS) adjacent to the transcription unit for the 40S-45S rRNA precursor.

In amphibians, the nucleotide sequences of the rRNA precursor have been completely clarified in only the two tetraploid species of Xenopus (Ajuh et al., 1991). In the other amphibian species examined, only the short nucleotide sequences of some rDNA fragments have been 
determined (Hillis et al., 1993). While the two species of Xenopus share almost identical rRNA coding regions, the ITS regions differ greatly between them (Ajuh et al., 1991). Sequence data are not apt to distinguish speciation events between different ploidy levels, nor do they contain information on the allopolyploidization events themselves (Kobel et al., 1998). According to an earlier estimate, $25 \sim 50 \%$ of duplicated genes have been silenced in the tetraploid X. laevis (Graf and Kobel, 1991; Hughes and Hughes, 1993). Comparisons of the rates of nucleotide substitution in various gene segments suggest that sequences with reduced coding constraints, for example, the intron, may be rapid enough to produce accumulated changes on a scale warranting their study ( $\mathrm{Li}$, et al., 1985; Gillespie, 1986). Ribosomal RNA exhibits an unusual evolutionary pattern featuring the interspersion of rapidly evolving segments among highly conserved regions that contain some of the most evolutionarily stable macromolecular sequences known (Gerbi, 1985).

Recent studies of the Japanese pond frog R. nigromaculata have made some progress. The complete mitochondrial genome has now been determined (Sumida et al., 2001), and examinations of the linkage groups have led to the mapping of 34 loci on ten chromosomes (Sumida and Nishioka, 2000). Nonetheless, the rRNA genes of this species have never been studied. In amphibian phylogeny, Xenopus laevis in the family Pipidae is considered more primitive than Rana nigromaculata in the family Ranidae.

In the present study, we determined the nucleotide sequence of the rRNA precursor from the Japanese pond frog Rana nigromaculata in order to evaluate the potential usefulness of the rRNA gene and the ITS regions for evolutionary studies on animals, particularly those focused on frogs.

\section{MATERIALS AND METHODS}

DNA sources. Japanese pond frogs, Rana nigromaculata, were collected from Ushita, Hiroshima City and used for artificial crossings to produce offspring in the laboratory. Genomic DNA was extracted from the livers of the offspring and purified by $\mathrm{CsCl}-\mathrm{EtBr}$ density gradient centrifugation according to the method reported by Sumida (1997). The frog sample (No. 31409) used was frozen and stored at the Institute for Amphibian Biology, Hiroshima University.

Cloning, sequencing, and data analysis. The EcoR I fragments of genomic DNA from $R$. nigromaculata were cloned into pBluescript II SK(+) and then subcloned into pUC19. Several series of deletion mutants were produced from this pUC19 subclone using a deletion kit (TaKaRa) according to the manufacturer's instructions. Once the cloned DNAs were purified by the alkaline lysis method (Davis et al., 1986) for DNA sequencing, the sequencings were performed on an automated DNA sequencer (ABI) by the DyeDeoxy termination method. Several clones were sequenced from the 5' and 3' sides, including one that was found to contain the rRNA precursor. Both strands of the $4.8 \mathrm{kbp} E c o \mathrm{R}$ I fragment containing the rDNA precursor were completely sequenced using various deleted subclones (total 99 clones). A DNA sequence analyzed using DNASIS Ver. 3.2 (Hitachi Software Engineering) revealed the nucleotide sequences of the 18S, $5.8 \mathrm{~S}$, and $28 \mathrm{~S}$ rRNA genes and two ITS regions. These genes and ITS regions were aligned with counterparts in other animals using ClustalW (Thompson et al., 1994), and the alignment data were used for the current analyses. The DNA sequence of Rana nigromaculata was deposited in the DDBJ database (accession number AB099628).

Window analysis. A window analysis was carried out to evaluate the variable and conserved regions within the $28 \mathrm{~S}$ rRNA gene. Initially, we created alignment data on the 28S rRNA genes of human, Rana, and two Xenopus species. The alignment contained 4,533 nucleotide sites, and the inclusion of deletion sites among them resulted in an increased length exceeding that of the actual sequenced $28 \mathrm{~S}$ rRNA gene. Next, the nucleotide diversity (Pi: equation 10.5 or 10.6 in Nei, 1987) per 5 nucleotide sites (= 1 window) was calculated using a computer program, DnaSP Ver. 3.52 (Rozas and Rozas, 1999). The $\mathrm{Pi}$ values were plotted along the sequence alignment. We also checked the plot patterns at another set of window sizes (1, 3, 10 and 20 nucleotide sites) and obtained the similar pattern at each setting. Thus, we showed only the first result ( 1 window $=5$ nucleotide sites) to simplify the description (see Fig. 3).

Phylogenetic analysis and substitution rate of the 28S rRNA gene. We conducted a phylogenetic analysis based on the 28S rRNA gene and examined the substitution rate of the sequences among anurans. In the following analyses we used 3,504 alignment sites, excluding all sites deleted from the alignment data mentioned above. Based on the alignment, genetic distances among the 28S rRNA genes of frogs and human were calculated by Kimura's two-parameter method (Kimura, 1980), and the phylogenetic tree was reconstructed by the neighborjoining (NJ) method (Saitou and Nei, 1987) using a computer program package, PHYLIP Ver. 3.5 (Felsenstein, 1993) and ClustalW (Thompson et al., 1994). Based on the resultant tree topology, the rate homogeneity for nucleotide substitutions among frogs was tested by Tajima's method (Tajima, 1993) using MEGA2 (Kumar et al., 2001). To calibrate evolutionary time, we also conducted branch length linearization (see section 9 in Nei and Kumar, 2000) based on the resultant NJ tree by the 


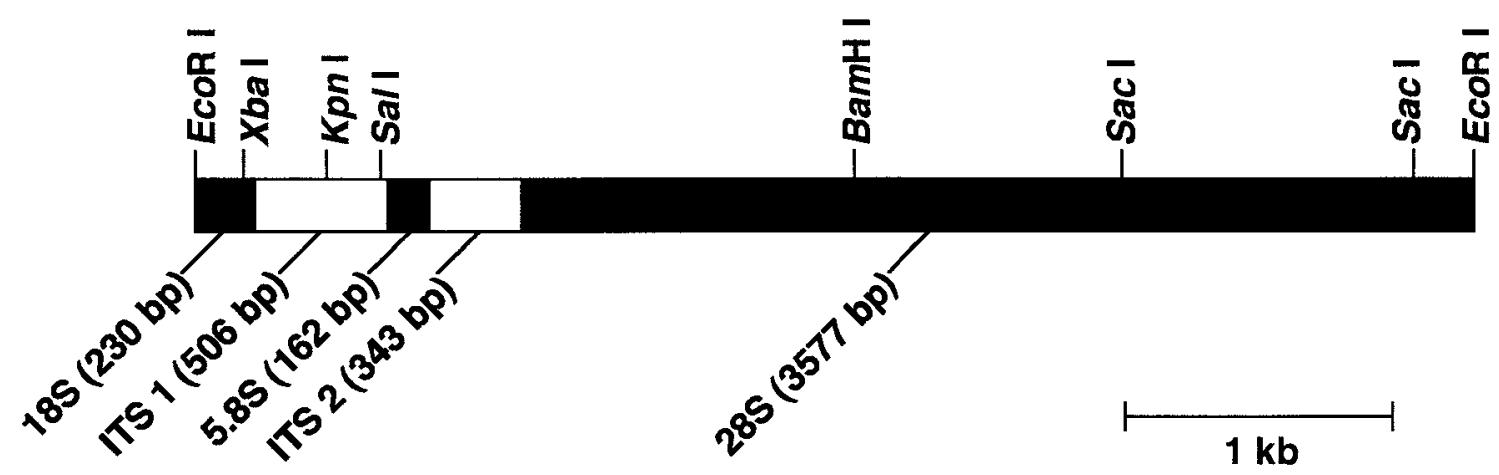

Fig. 1. Scheme of the sequenced ribosomal precursor unit of R. nigromaculata. ITS1 and ITS2 denote first and second internal transcribed spacers, respectively. The locations of the restriction sites for EcoR I, Xba I, Kpn I, Sal I, BamH I and Sac I are shown.

Table 1. Nucleotide sequence length (bp) in different segments of the ribosomal precursor unit of R. nigromaculata, $X$. laevis, $X$. borealis and human.

\begin{tabular}{|c|c|c|c|c|}
\hline Segment & R. nigromaculata & X. laevis $^{\mathrm{a}}$ & X. borealis $^{\mathrm{a}}$ & Human $^{\mathrm{b}}$ \\
\hline 5'-ETS & - & 712 & 612 & 3656 \\
\hline $18 \mathrm{~S}$ & $230 *$ & 1826 & 1826 & 1871 \\
\hline ITS1 & 506 & 557 & 554 & 1095 \\
\hline $5.8 \mathrm{~S}$ & 162 & 162 & 162 & 157 \\
\hline ITS2 & 343 & 262 & 336 & 1155 \\
\hline $28 \mathrm{~S}$ & $3577^{*}$ & 4115 & 4128 & 5035 \\
\hline 3'-ETS & - & - & - & 381 \\
\hline Total & 4818 & 7634 & 7618 & 13350 \\
\hline
\end{tabular}

Table 2. Nucleotide composition in different segments of the ribosomal precursor unit of R. nigromaculata, X. laevis, X. borealis and human.

\begin{tabular}{|c|c|c|c|c|c|c|c|c|c|c|c|c|c|c|c|c|}
\hline \multirow[t]{2}{*}{ Segment } & \multicolumn{4}{|c|}{ R. nigromaculata } & \multicolumn{4}{|c|}{ X. laevis $^{\mathrm{a}}$} & \multicolumn{4}{|c|}{$X$. boreali $^{\mathrm{a}}$} & \multicolumn{4}{|c|}{ Human $^{b}$} \\
\hline & $\% \mathrm{~A}$ & $\% \mathrm{G}$ & $\% \mathrm{C}$ & $\% \mathrm{~T}$ & $\% \mathrm{~A}$ & $\% \mathrm{G}$ & $\% \mathrm{C}$ & $\% \mathrm{~T}$ & $\% \mathrm{~A}$ & $\% \mathrm{G}$ & $\% \mathrm{C}$ & $\% \mathrm{~T}$ & $\% \mathrm{~A}$ & $\% \mathrm{G}$ & $\% \mathrm{C}$ & $\% \mathrm{~T}$ \\
\hline 5'-ETS & \multicolumn{4}{|c|}{-} & 10.7 & 37.2 & 45.9 & 6.2 & 10.0 & 37.1 & 44.3 & 8.7 & 5.7 & 39.7 & 39.6 & 15.1 \\
\hline $18 \mathrm{~S}$ & $22.0^{*}$ & $30.2^{*}$ & $25.9 *$ & $22.0^{*}$ & 23.7 & 28.3 & 25.5 & 22.5 & 23.8 & 28.2 & 25.5 & 22.5 & 22.4 & 29.4 & 26.7 & 21.5 \\
\hline ITS1 & 15.8 & 39.1 & 38.9 & 6.1 & 12.4 & 41.3 & 42.9 & 3.4 & 15.5 & 38.8 & 39.7 & 6.0 & 7.7 & 40.3 & 39.4 & 12.7 \\
\hline $5.8 \mathrm{~S}$ & 19.1 & 30.2 & 30.2 & 20.4 & 18.5 & 29.6 & 30.2 & 21.6 & 18.5 & 29.6 & 29.6 & 22.2 & 19.7 & 28.7 & 28.7 & 22.9 \\
\hline ITS2 & 7.3 & 36.7 & 45.5 & 10.5 & 5.0 & 35.1 & 53.1 & 6.9 & 10.4 & 37.5 & 44.3 & 7.7 & 5.1 & 40.0 & 43.0 & 11.8 \\
\hline $28 \mathrm{~S}$ & $18.3^{*}$ & $36.0 *$ & $30.7^{*}$ & $15.0^{*}$ & 18.4 & 35.5 & 30.2 & 16.0 & 18.6 & 35.2 & 30.1 & 16.1 & 15.9 & 36.0 & 33.2 & 14.9 \\
\hline 3'-ETS & \multicolumn{4}{|c|}{-} & & & & - & & & & - & 3.1 & 40.9 & 40.9 & 15.0 \\
\hline
\end{tabular}

*not complete (partial). ${ }^{a}$ Data from Ajuh et al. (1991). ${ }^{b}$ Data from Gonzalez and Sylvester (1995).

Table 3. Percent nucleotide sequence divergences of ribosomal RNA genes among Rana, Xenopus and human.

\begin{tabular}{|c|c|c|c|}
\hline Combination & $\begin{array}{c}\text { 5.8S rRNA } \\
(162 \mathrm{bp})\end{array}$ & $\begin{array}{c}\text { 18S rRNA } \\
\left(230 \mathrm{bp}^{*}\right)\end{array}$ & $\begin{array}{l}\text { 28S rRNA } \\
(3571 \mathrm{bp} *)\end{array}$ \\
\hline R. nigromaculata-X. laevis $^{\mathrm{a}}$ & 3.2 & 0.4 & 5.1 \\
\hline R. nigromaculata- X. borealis ${ }^{\mathrm{a}}$ & 3.8 & 0.4 & 5.3 \\
\hline R. nigromaculata- Human ${ }^{\mathrm{b}}$ & 4.6 & 2.7 & 9.5 \\
\hline X. laevis $^{\mathrm{a}}-$ Human $^{\mathrm{b}}$ & 2.6 & 2.2 & 8.8 \\
\hline$X$. borealis $^{\mathrm{a}}-$ Human $^{\mathrm{b}}$ & 1. 9 & 2.7 & 9.1 \\
\hline X. laevis $^{\mathrm{a}}-X$. borealis $^{\mathrm{a}}$ & 0.6 & 0.4 & 0.9 \\
\hline
\end{tabular}

*not complete (partial). ${ }^{a}$ Data from Ajuh et al. (1991). ${ }^{\mathrm{b}}$ Data from Gonzalez and Sylvester (1995). 
LS method using the Kitsch program in PHYLIP.

Sequence data and phylogenetic analysis based on the 5.8S rRNA gene. The 5.8S rRNA gene sequences used in the phylogenetic analyses were from the 35 vertebrate species shown in Figure 6. The method used to reconstruct the phylogenetic tree was the same as that used for the 28S rRNA genes. The nucleotide sequence of Giardia intestinalis (Protista) was used as an outgroup to construct the phylogenetic tree.

\section{RESULTS}

Gene content and gene arrangement of the sequenced ribosomal precursor unit of $R$. nigromaculata. The whole $E c o$ R I fragment of the ribosomal precursor

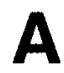

1

60

R.nigromaculata GAATTC-CCAGTAAGTGCGGGTCATAAGCTCGCGTTGATTAAGTCCCTGCCCTMTGTACA X.laevis X.borealis Human

GAATTC-CCAGTAAGTGCGGGTCATAAGCTCGCGTTGATTAAGTCCCTGCCCTTTGTACA GAATTC-CCAGTAAGTGCGGGTCATAAGCTCGCGTTGATTAAGTCCCTGCCCTTTGTACA GAATTCCCGAGTAAGTGCGGGTCATAAGCTTGCGTTGATTAAGTCCCTGCCCTTTGTACA

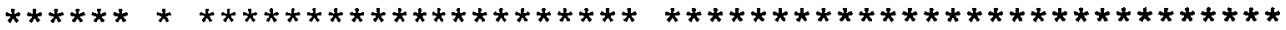

61

120

R.nigromaculata CACCGCCCGTCGCTACTACCGATTGGATGGTTTAGTGAGGTCCTCGGATCGGCCCCGCCG X.laevis X.borealis Human CACCGCCCGTCGCTACTACCGATTGGATGGTTTAGTGAGGTCCTCGGATCGGCCCCGCCG CACCGCCCGTCGCTACTACCGATTGGATGGTTTAGTGAGGTCCTCGGATCGGCCCCGCCG CACCGCCCGTCGCTACTACCGATTGGATGGTTTAGTGAGGCCCTCGGATCGGCCCCGCCG

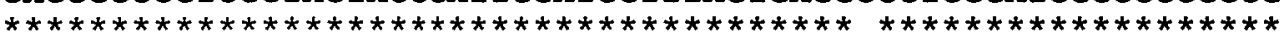

121

180

R.nigromaculata GGGTCGGCG-ACGGCCCTGGCGGAGCGCCGAGAAGACGATCAAACTTGACTATCTAGAGG X. laevis X.borealis Human GGGTCGGCC-ACGGCCCTGGCGGAGCGCCGAGAAGACGATCAAACTTGACTATCTAGAGG GGGTCGGCA-ACGGCCCTGGCGGAGCGCCGAGAAGACGATCAAACTTGACTATCTAGAGG GGGTCGGCCCACGGCCCTGGCGGAGCGCTGAGAAGACGGTCGAACTTGACTATCTAGAGG

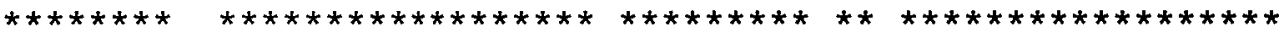

181

R.nigromaculata AAGTAAAAGTCGTAACAAGGTTTCCGTAGGTGAACCTGCGGAAGGATCATTA X.1aevis X.borealis AAGTAAAAGTCGTAACAAGGTTTCCGTAGGTGAACCTGCGGAAGGATCATTA Human AAGTAAAAGTCGTAACAAGGTTTCCGTAGGTGAACCTGCGGAAGGATCATTA AAGTAAAAGTCGTAACAAGGTTTCCGTAGGTGAACCTGCGGAAGGATCATTA

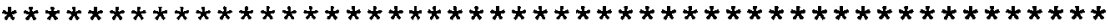

1

R.nigromaculata GCAAGACTCTTAGCGGTGGATCACTCGGCTCGCGCGTCGATGAAGAACGCAGCTAGCTGC $x$. laevis $\mathrm{x}$. borealis TCGCGACTCTTAGCGGTGGATCACTCGGCTCGTGCGTCGATGAAGAACGCAGCTAGCTGC TCGCGACTCTTAGCGGTGGATCACTCGGCTCGTGCGTCGATGAAGAACGCAGCTAGCTGC ---CGACTCTTAGCGGTGGATCACTCGGCTCGTGCGTCGATGAAGAACGCAGCTAGCTGC

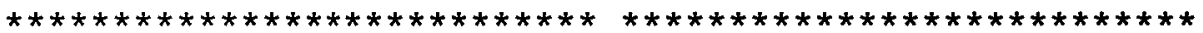

61

120

R.nigromaculata GAGAATTAGTGTGAATTGCAGGACACATTGATCATCGACACTTCGAACGCACCTTGCGGC X.laevis $x$.borealis Human GAGAATTAGTGTGAATTGCAGGACACATTGATCATCGACACTTCGAACGCACCTTGCGGC GAGAATTAGTGTGAATTGCAGGACACATTGATCATCGACACTTCGAACGCACCTTGCGGC GAGAATTAATGTGAATTGCAGGACACATTGATCATCGACACTTCGAACGCAC-TTGCGGC

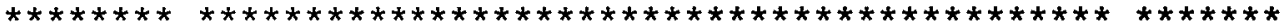

121 162

R.nigromaculata $\mathrm{x}$. laevis $x$.borealis Human

CCCGGGTTCCTCCCGGGGCCGCGCCTGTCTGAGGGTCGCTCC CCCGGGTTCCTCCCGGGGCCACGCCTGTCTGAGGGTCGCTCC CCCGGGTTCCTCCCGGGGCTACGCCTGTCTGAGGGTCGCTCC CCCGGGTTCCTCCCGGGGCTACGCCTGTCTGAGCGTCGCTT-

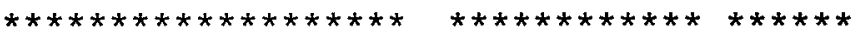


1

R.nigromaculata GATTGGCTCTAAGGGCTGGGTCGGTCGGGCTGGGGCGCGAAGCGGGGCTGGGCGCGCGCC X. laevis X.borealis GATTGGCTCTAAGGGCTGGGTCGGTCGGGCTGGGGCGCGAAGCGGGGCTGGGCACGCGCC GATTGGCTCTAAGGGCTGGGTCGGTCGGGCTGGGGCGCGAAGCGGGGCTGGGCACGCGCC Human GATTGGCTCTAAGGGCTGGGTCGGTCGGGCTGGGGCGCGAAGCGGGGCTGGGCGCGCGCC

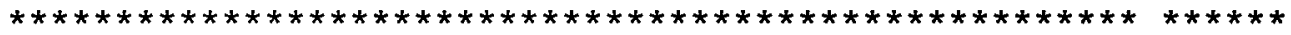

61

120

R.nigromaculata $\mathrm{X}$. laevis $\mathrm{X}$.borealis

GCGGCTGGACGAGGCGC $-G C C C C C G C C$ Human GCGGCTGGACGAGGCGC--GCGGCTGGACGAGGCGCGCGCCCCCCCCACGCCCGGGGCACCCCCCTCGCGGCCCTCCCC

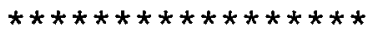

- CCGCCTCCCСССTCCCCGGGGG

--------CGGTCCCCCCCCCTCGCGGGGGGGGC-----------_GGCCGGGCG CCCCCGCTCCCCGTCCTCCCCCCTCCCCGGGGGAGCGCCGCGTGGGGGCGCGGCGGGGGG

R.nigromaculata $\mathrm{X}$. laevis $X$.borealis Human

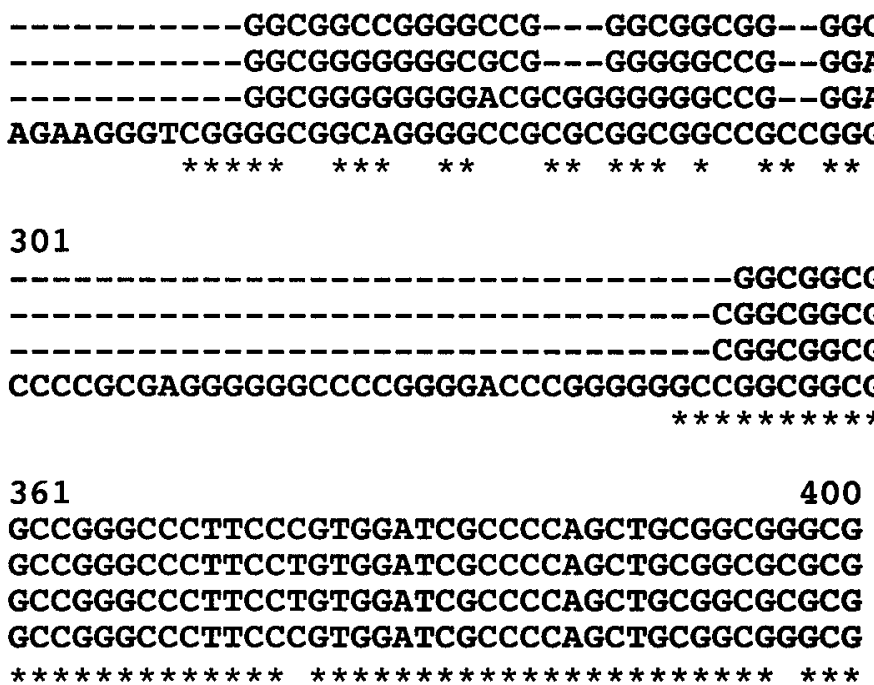

R.nigromaculata X. laevis $x$.borealis Human

$\star \star * \star * * * * * * * * * \quad * * * * * * * * * * * * * * * * * * * * * * \quad * * *$

Fig. 2. Aligned sequences of a 3 '-side 232-bp segment of the 18S rRNA gene (A), a complete 162-bp segment of the 5.8S rRNA gene (B), and 400-bp segment of the $28 \mathrm{~S}$ rRNA gene (C) of $R$. nigromaculata, X. laevis, X. borealis and human. Asterisks indicate nucleotide sequences that are conserved among four taxa. The 28S rRNA gene sequence of $R$. nigromaculata corresponds to nucleotide sites 2391-2621.

unit of $R$. nigromaculata was 4,818 bp in length and contained the following segments: $5^{\prime}-18 \mathrm{~S}$ rRNA - ITS $1-5.8 \mathrm{~S}$ rRNA - ITS 2 - 28S rRNA - 3' (Fig. 1, Table 1). The 3'side segment of the $18 \mathrm{~S}$ rRNA gene was $230 \mathrm{bp}$ and the 5 '-side segment of the $28 \mathrm{~S}$ rRNA gene was $3,577 \mathrm{bp}$. The 5.8S rRNA gene was completely sequenced with a length of $162 \mathrm{bp}$. The ITS 1 and ITS 2 were $506 \mathrm{bp}$ and $343 \mathrm{bp}$, respectively. While these ITS segment lengths were not different from those of the two Xenopus species, they were very different from those of human.

Base composition and nucleotide divergences. Table 2 shows the nucleotide compositions in different segments of the ribosomal precursor unit. The frequen- 
cies of nucleotides $\mathrm{G}$ and $\mathrm{C}$ were $56 \sim 67 \%$ in the segments of the three genes, whereas they were more than $78 \%$ in the two ITS segments. The ITS regions of Rana had a high nucleotide bias, as did those of the two Xenopus species for ribosomal regions, where the secondary structure requires the formation of strong, double-stranded stems due to the stronger hydrogen bonding of the base pairs formed by $G$ and $C$ (Larson and Wilson, 1989). The nucleotide sequence divergences between Rana and Xenopus were $3.2 \sim 3.8 \%, 0.4 \%$ and $5.1 \sim 5.3 \%$ in $5.8 \mathrm{~S}, 18 \mathrm{~S}$ and 28S rRNA genes, respectively, and those between human and Rana or Xenopus were $1.9 \sim 4.6 \%, 2.2 \sim 2.7 \%$ and $8.8 \sim 9.5 \%$ in $5.8 \mathrm{~S}, 18 \mathrm{~S}$ and $28 \mathrm{~S}$ rRNA genes, respectively (Table 3). In the 5.8S rRNA gene, the nucleotide sequence divergences between Rana and Xenopus (3.2 3.8\%) were larger than those between Xenopus and human $(1.9 \sim 2.6 \%)$. The large divergences between two frog genera were caused by a few nucleotide changes found only in Rana (i.e., autapomorphic substitutions). Because the length of 5.8S rRNA gene is very short (approx. $160 \mathrm{bp}$ ), a slight number of autapomorphic changes affect the divergence values. Thus, the values of nucleotide sequ- ence divergences among frogs and human shown here do not represent directly their phylogenetic relationships (The 5.8S rRNA sequence data support the monophyly of anurans; see below and Fig. 6). Finally, the nucleotide sequences in the ITS regions of human could not be aligned with those of Rana and Xenopus.

\section{Comparison of the nucleotide sequences of Rana} with those of Xenopus and human.

(i) 18S rRNA gene. Nucleotide sequences were determined in a 230-bp segment of the 3'end of the 18S rRNA gene (Fig. 2A). There was no variation between the sequenced 230-bp segment of Rana and that of Xenopus, whereas 7 nucleotide substitutions and 2 gap sites were identified in the comparison between Rana and human.

(ii) 5.8S rRNA gene. The nucleotide sequences of the 5.8S rRNA gene were aligned in the complete 162-bp segment among Rana, the two Xenopus species, and human (Fig. 2B). Five nucleotide substitutions were found between Rana and Xenopus, and 4 gap sites were identified in the comparison between Rana and human. (Fig. 2B).

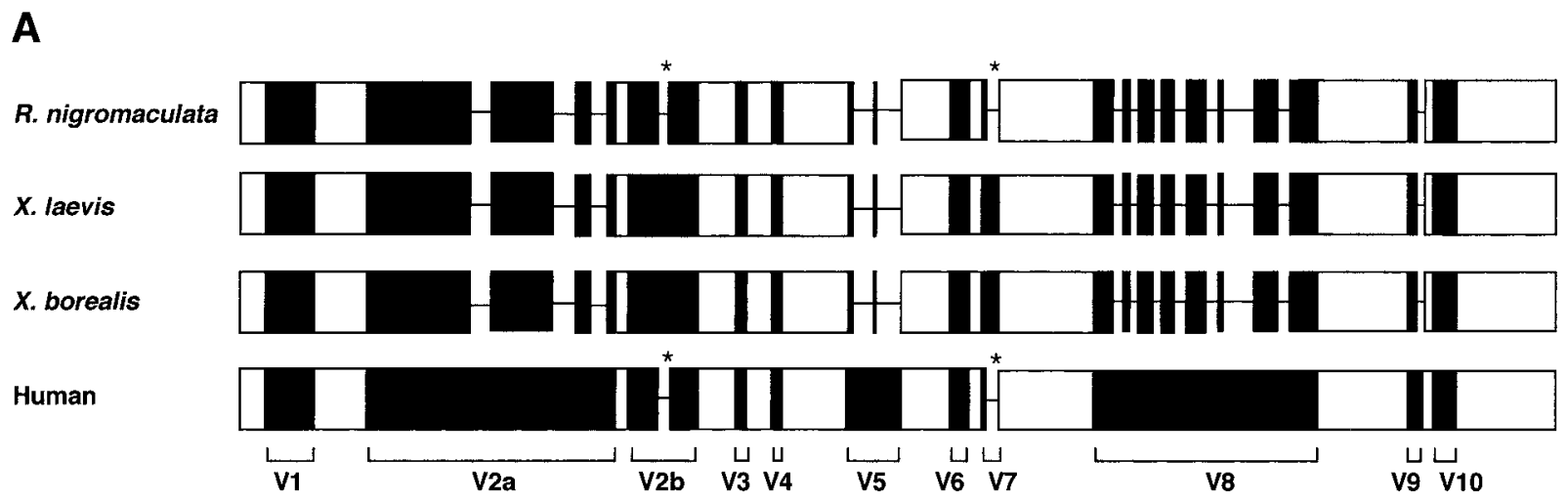

B

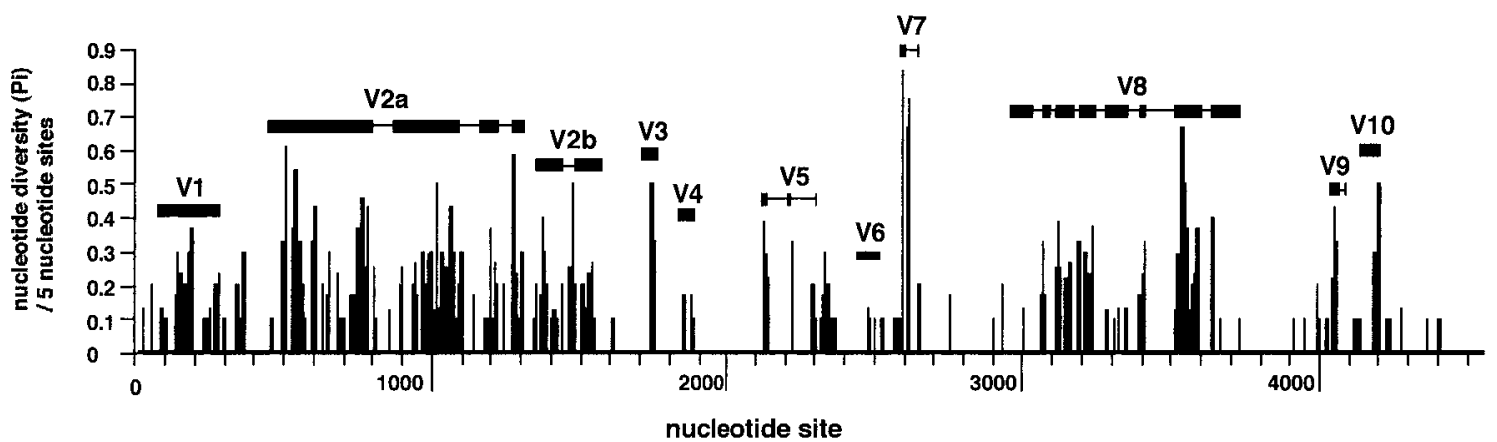

Fig. 3. Distribution of conserved and variable regions and the window analysis in the 28S rRNA genes of R. nigromaculata, X. laevis, $X$. borealis and human. (A) The variable regions deduced from sequencing are shown as black tracts (V V10), and the conserved regions are in white. These tracings are drawn in the $5^{\prime} \rightarrow 3^{\prime}$ orientation from the $28 \mathrm{~S}$ rRNA segments shown in Ajuh et al. (1991) (X. laevis and X. borealis) and Gonzalez and Sylvester (1995) (human). Thin bars show lengthy deletions ( $>20$ bases). Asterisks indicate the lengthy deleted region only shared in Rana and Human. (B) Window analysis. The genetic diversities (Pi) per 5 nucleotide sites are indicated along the nucleotide sequences. The portions corresponded to the variable regions and lengthy deletions are indicated by thick and thin bars, respectively. Deleted nucleotides were not counted as nucleotide changes, hence the Pi of the portions with lengthy deletions are low. 
(iii) 28S rRNA gene. Based on nucleotide homology, the 3,577-bp segment of the 28S rRNA gene of Rana nigromaculata corresponded to sites 1-3608 in the $28 \mathrm{~S}$ rRNA gene sequence of Xenopus laevis and sites 1- 4453 in that of human. The 28S rRNA gene segment of Rana was aligned with the counterparts of the two Xenopus species and human (Figs. 2C and 3A). Compared with the 28S rRNA gene of human, that of Rana had an abundance of lengthy ( $>20$ bases) deletions (thin bars in Fig. 3A). As most of these deletions were also observed in the two Xenopus species, the lengths of the 28S rRNA genes of the three amphibian species were much shorter than that of human. At the same time, however, it should be noted that the two deleted regions indicated by asterisks were only common in Rana and human (Fig. 3A). These sites could have been caused by nucleotide insertion only in the Xenopus lineage. A previous investigation showed that the 28S rRNA gene of vertebrates had 11 " variable regions" with numerous polymorphic and gap sites between human and Xenopus (Ajuh et al., 1991). When examined under electron microscopic, these regions were thought to correspond to the loop regions in secondary structures of $28 \mathrm{~S}$ rRNA (Ajuh et al., 1991). In the present study, a window analysis was carried out to assess the presence of these variable regions in the $28 \mathrm{~S}$ rRNA gene of Rana. Based on the result of this window analysis (Fig. 3B), the nucleotide diversities (Pi, see Nei, 1987) were plotted in each window (5 nucleotide sites) along the 28S rRNA gene alignment. Similar plot patterns were obtained when another set of window sizes ( 1 , $3,10,20$ nucleotide sites) was attempted (data not shown). The analysis showed 9 regions where the nucleotide sites with high diversities were concentrated $(>0.2)$. The positions of these regions closely corresponded with those of the "variable regions (V1, 2a, 2b, 3, $5,7,8,9$, and 10)" previously reported. Though the values of nucleotide divergences were somewhat low $(<0.2)$, a throng of polymorphic sites were also packed into the sites corresponding to the remaining two variable regions (V4 and V6). Furthermore, lengthy deletions observed in the 28S rRNA gene of Rana were concentrated in the highly polymorphic regions (V2a, 2b, 5, 7, 8 and 9). These results showed that the "variable regions" observed in human and Xenopus are also present in the 28S rRNA gene of Rana (Fig. 3B). Thus, the secondary structure of the 28S rRNA of Rana seemed to be similar to those of the other known vertebrates.

(iv) ITS regions. There were seven short tracts of completely or almost completely conserved sequences embedded in the largely divergent sequences of the two ITS regions, ranging in length from 5 to 27 nucleotides (Fig. 4). Two of the seven were embedded in the ITS 1 (Fig. $4 \mathrm{~A}$ ) and the other five were embedded in the ITS 2 (Fig. 4B). Marked tendencies towards 'simple sequence' patterns such as homopolymeric tracts, pyrimidine tracts, and purine tracts were observed (Fig. 4).

\section{Phylogenetic analysis.}

(i) 28S rRNA gene. Although partial sequences of the 28S rRNA gene have been reported in many amphibians, the complete sequences of this gene are known in only two Xenopus species. To examine the usefulness of the $28 \mathrm{~S}$ rRNA gene sequences for evolutionary studies of anurans, we conducted a phylogenetic analysis by adding the long 28S rDNA sequence of Rana. Figure 5 shows the NJ tree based on the 3,504 alignment sites of the 28S rRNA gene. As shown in this figure, the long $28 \mathrm{~S}$ rRNA gene sequence data reconstructed the monophyly clade of Xenopus with a high BP value (1000) and deep divergence between Rana and Xenopus. Moreover, the branch lengths of the tree seemed to be equal between the frog species, suggesting that the rate of the $28 \mathrm{~S}$ rRNA gene was constant in these animals. The relative rate test (Tajima, 1993) was used to investigate this likelihood. For all tested frog lineages, the rate constancy hypothesis did not reject with high statistical values (Table 4).

(ii) 5.8S rRNA gene. The nucleotide sequence divergences of the 5.8S rRNA gene were calculated among various phyla to evaluate the utility of this gene for phylogenetic analysis. The nucleotide sequence divergences of the 5.8S rRNA gene were 3.2 3.8\% between two frog genera (Rana and Xenopus), 4.0 4.6\% between Rana and mammals, 4.6 12.2\% between Rana and fishes, 17.0 34.3\% between Rana and invertebrates, and 60.3 70.3\% between Rana and Protista. The mean sequence divergences of the 5.8S rRNA gene within kingdoms were $62.9 \%$ in Protista and $21.0 \%$ in Animalia, and those within individual phyla were $6.1 \sim 7.5 \%$ in the three phyla Platyhelminthes, Mollusca, and Chordata, and 29.7\% in the phylum Arthropoda (Table 5). The mean sequence divergences of the 5.8S rRNA gene were 67.9\% between the two kingdoms Protista and Animalia, 26.8\% among the four invertebrate phyla, and $26.1 \%$ between the phylum Chordata and the four invertebrate phyla (Table 5). The phylogenetic analysis was carried out using the nucleotide sequences of the 5.8S rRNA gene of various taxa. A phylogenetic tree based on the complete set of nucleotide sequences of the 5.8S rRNA gene showed that each phylum formed a cluster, and that the divergences within the Protista, invertebrates, and Chordata were the largest, medial, and smallest, respectively (Fig. $6)$.

\section{DISCUSSION}

The ITS regions. The internal transcribed spacer (ITS) regions diverge extensively among the one Rana and two Xenopus species, but several short sequences that seem to be important in function are conserved among these species. As discussed previously, a difference noted in 
the spacing between the boxed tracts (see Fig. 4) among the one Rana and two Xenopus species implies evolutionary divergence by insertions and deletions in the intervening ITS tracts (Furlong and Maden, 1983; Furlong et al., 1983). The four tracts in the ITS 2 are well conserved between the two Xenopus and one Rana species. Underlined sequences of Rana denote tracts of 10 or more nucleotides in the spacers consisting of purines only, pyrimidines only, or a single type of base. These simple sequence tracts are not conserved in the two Xenopus species. When we try to account for their conservation in Rana, it remains unclear whether they have been left intact merely by chance or whether they are under some degree of functional constraint. Large parts of the tran-

\section{A}

$X$.borealis

$X .1$ aevis

R.nigro.

$X$. borealis

X. laevis

R.nigro.

$X$.borealis

$X .1$ aevis

R.nigro.

$X$.borealis

$X .1$ laevis

R.nigro.

$X . b o r e a l i s$

$X .1$ aevis

R.nigro.

$X$.borealis

$X .1$ aevis

R.nigro.

X.borealis

$X .1$ aevis

R.nigro.

X.borealis

$X$. laevis

R.nigro.

X.borealis

$X .1$ aevis

R.nigro.

$X$.borealis

$X$. laevis

R.nigro.

X.borealis

$X .1$ aevis

R.nigro.

$X . b o r e a l i s$

$X .1$ laevis

R.nigro.
1

ACGAGAGAG

60

ACGAGA $\frac{\text { CCGAGAGAGACAGGGAGGCGGCCCGCCGGCCCGTCCTCGCCTCGTCCGACCCGAGACCCC }}{\star \star \star \star \star}$

61

120 CACGAGCCGCCGGGGCCGCGTGGGAGAGGGAGGCGCCGGGCCGCGCGGCCCCCGGCGCCC

121

180

TGCGAGAGCGCGGCTCTGCCGCACCCCCGCCACCGTCCCGGCTCCCCCCGCGGACGACGA CGCCCCCCCCCCACGGGGGGGGGGCGGCCGCCCCGAAAGGGACGACGAGGAACCCCCAGA CTCCCCCGCAACCAGCCCCGCGGGACCCCAGAGGAACGCGCCGGCGGGAGGGGGAGGCGC 181

AGGTCCGGGCGCGGGCTCCCGCCCGCCCCGACACGAGGAGAGAGCGGAAAAGGAACAAC GGCCCCGGCGAGGGGGCGGCGGCGGCCCCGGGTCCACCCCGGGCCCGCCCGCCCGCCTCC GGAGTCGCGGCGAGGGGGGGGGGCATCCCCCCTCCGCGCCCGGCACCCGCGAGCCCTCCC

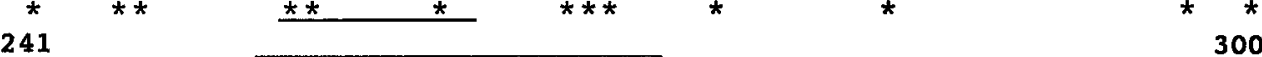
CAAAAAAAACGAGCCCGGGTACCTAGCCGGGGGGGGGCGAGGGCGGGGACGGGGGGCAGA CGCCGCGGGCCCGCCCGGGTACCTAGCCGGGGCCGGGGCGCGGGGGCTGGCGCGGGAGCG GCCGGCAGGCCGAGCCGGGTACCGCTCGGGCCCGCGTCCGCCCCGACCCGGGGGGGGCGG 301

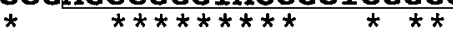
* $*$ * $* * * 360$ GGC-DCCCCCCCCCCCTCCCGGGGGT GGCGGCCCCAGGGCCGTCCGGCCTCCCCGCGTCCGCCTCCCGCGACCCGCCCCGGGCGGT $\underset{*}{\text { AGGGGCCCGGAAGGTTTGGAAGCCTCGAGACGGGAGCCCCTTCGCGGGGGGCTCCCGGCC }}$ 361 CGAAGACCCCGGCCCACGGCCGGCGGCGGCGACGAGGGGCGAGCCG--TCCGGAGGCGGG CGAAGACCCCGCCCGCCGGGCGGCGGGAGGGCCGGGAGG-GAGCCGGGGAGGG--GAGGG

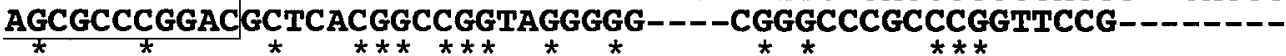
421
GG-CGGGCGCGGAGGGGGGACGGGGGGGAGGCGGAGGTCACGGCCGGACGCGGCCGCGTC GGGAGGCGGCGGCGAGCCCGGCCGGGCGCCGCCGCCGCAGGACCCCCGTCCCCGTCCCGC

$481 \quad 540$

CTCCGCCCGCCCCCCCCCCGTCTGTCCGCGCCCCGCCCCGCGCGCCGGTCGCGTCAGTCC CCGCCCCCGCCGGCCC$541 \quad 600$ CGCCGCCCCGTCGGCGGCGCCCCGGGGCGCCCGGGGCCCGGGGGCCCGCCCCGTCCAGCT

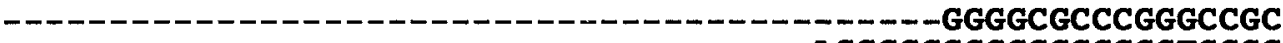

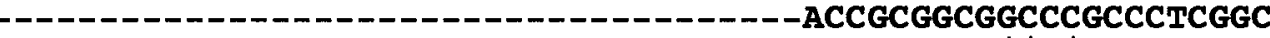
601 ***

601

CCACGGCGCCCGCGCGCGCCGGTACCCCTGCCGCGA--GGCAACGAGA-GAGAAAAACAA ACCGCCTCAGCGGCAGCACCGGTAGCCCTGCCGAGACCGAAAAGGAAAACCGACCGACGC CAGGGCGAGAAACCACGACGTCCCCCTTGTCGACCT--TACCGAAAGGAAAAAAAAAAAA 661

CGAAAAAAATC TCGGCGAGAGC CGAAAAAA-GA 


\section{B}

\section{X.borealis \\ X. laevis \\ R.nigro. \\ X.borealis \\ X. laevis \\ R.nigro.}

X.borealis

$X .1 a e v i s$

R.nigro.

X.borealis

$X .1$ aevis

R.nigro.

1 GACGTCCATCGCCCCCGCCGGGTCCCCGACCCGGGGAAAACGGGCGGCGCGGCTGGGGCC GACGTCCATCGCCCCCGCCGGGTCCC-GTCCCGG----_CGCGGAGGCGCGGCTGGGGCC TCCGTCGGTCGCCCC-GCCGGG--- -

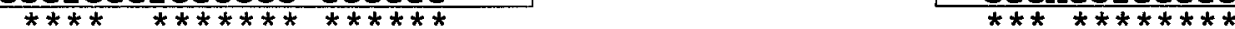
$61 \quad 120$ TCGCAGGGGTCGAGGGACGCCCCCCCACCGCCCTTCCGGGGGAGGTGAGGGGGCCCCGCG TCGCAGGGGCGCGCCG- TCGCAGGGGCCCGGAAGAGGGAGCCGGGGCGGAGGGCGCGGGCGGTCCCGGCGAGGGGTC

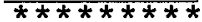

180

121 ACCCCTTCGTC TCCGGGGCCCCGCGCCCGACGCCGCGCCCTCCTCCCCTCTCCCGGCCGGGCCCCTTCGTC 181 $* * * * * * * * * *$ CCCAAGGCCAGACCCCGACCATCCCGGCGGCCCCCCC 240 CCCCAAGGCCAGACCCCCGGCCCGGCGCCCGGGCCCCGG-1CCCGAAGGCCAGACCCCTTCCGCCTCGGGGGTCCCCCCTCCGCGAGGGCTCCGTCCCCCT $* \star * * * * * * * * * * * * * * \quad * \quad * * * * * * *$

300

241 -_CAGGGCCCCGGCGCGGCTGTCTGTGGGAAACCGATTTCACGGCTGCCGGCGCCG -----CCCGGCCGGCG_GCGGCTGTCTGTGGATCCC-_--TTCACGGCTGCCGCCCCGG CTCCCG-AAGGGGGCCGCGCGGCTGTCTGTGGCTCA--GGCAGCAGGGCTGACCGCGCGG

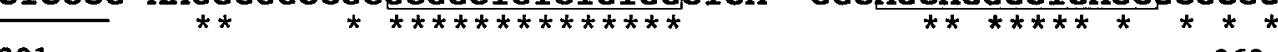
GGGCGCTGGGGACCC----GCCGGGGCGGGAAGAGCCCCCGGGCGGGCCGGGGCCGGGGA

X.borealis x.laevis R.nigro.

X.borealis $X .1$ aevis CGGCCCCCCGGGGCCCCGGCCCGCCGGCGGGAGCGGGCCCGGCC CCCCGC361 $* * * * * *$

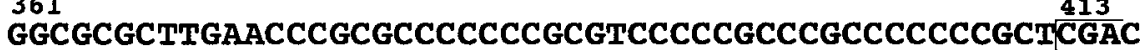
413 - CCCCCCCCGGGCCGCGGCCCCGCGCCCCCCCCCCCCCCCACGAC

R.nigro.

Fig. 4. Aligned sequences of internal transcribed spacers ITS1 (A) and ITS2 (B) of $R$. nigromaculata, X. laevis and X. borealis. Boxes denote nucleotide sequences that are conserved between two Xenopus species. Asterisks indicate the nucleotides that are conserved among three taxa. Lines indicate tracts of eight or more nucleotides of which show strong bias towards a single type of base.

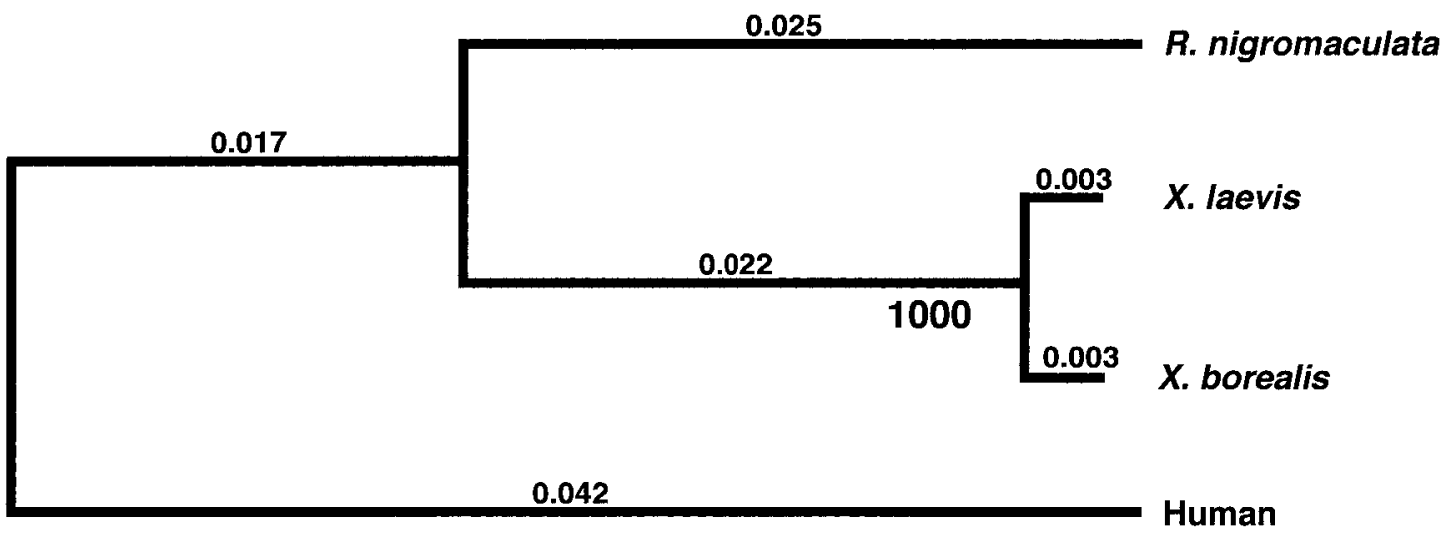

0.01

Fig. 5. A phylogenetic tree constructed by the NJ method based on the nucleotide sequence divergences of the $28 \mathrm{~S}$ rRNA gene among $R$. nigromaculata, $X$. laevis, $X$. borealis and human. The 3,504 sites without gaps were used for phylogenetic tree reconstruction, and human was used as an outgroup. The scale bar represents branch length in terms of nucleotide substitutions per site. The branch lengths of linearized tree were indicated above nodes. The bootstrap value (1000) of Xenopus lineage was calculated by 1,000 replicates. 


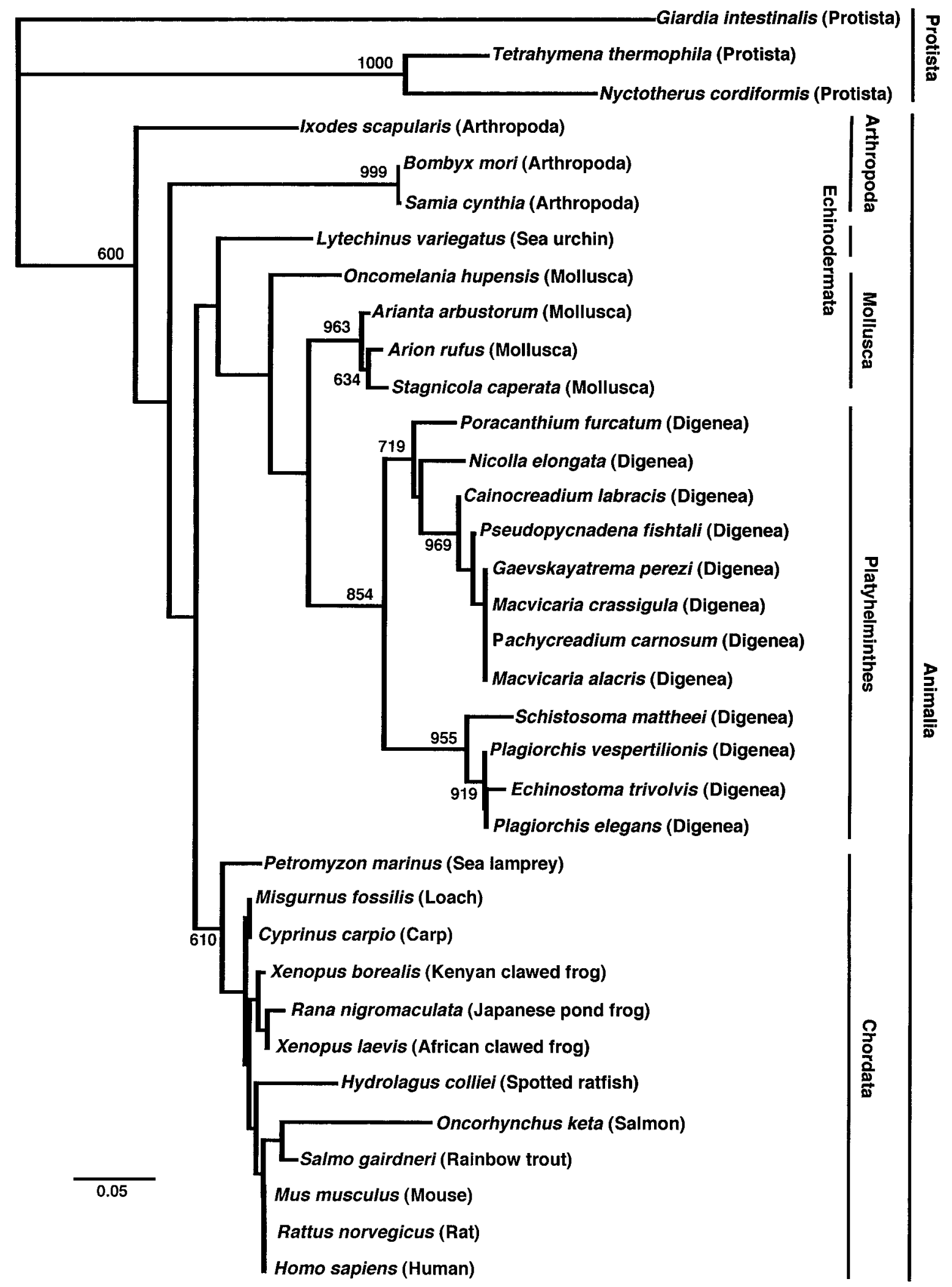


Table 4. Tajima's rate test (Tajima, 1993) for the 28S rRNA gene of frogs.

\begin{tabular}{lllcc}
\hline \hline \multicolumn{2}{c}{ Species } & Chi-square* & $P$ \\
\cline { 1 - 2 } Outgroup & \multicolumn{2}{c}{ Ingroup } & & \\
\cline { 1 - 2 } Human & $R$. nigromaculata & X. laevis & 0.17 & 0.69 \\
Human & R. nigromaculata & X. borealis & 0.11 & 0.74 \\
Human & $X$. laevis & X. borealis & 0.07 & 0.80 \\
R. nigromaculata & $X$. laevis & X. borealis & 0.00 & 1.00 \\
\hline
\end{tabular}

*The Chi-square value has 1 degree of freedom. When the value is $>3.841$, the constant rate hypothesis between the pair of sequences is rejected by $P=0.05$ level. All tested pairs of the $28 \mathrm{~S}$ rRNA gene sequences did not reject the hypothesis.

Table 5. Percent nucleotide sequence divergences of the 5.8S rRNA gene among 35 species at the various taxonomic levels.

\begin{tabular}{llccc}
\hline \hline \multicolumn{2}{c}{ Taxa (No. of phylum or class / No. of species) } & \multicolumn{2}{c}{ Nucleotide sequence divergences } \\
\cline { 3 - 4 } & & \multicolumn{2}{c}{ Range } & Average \\
\hline \multirow{2}{*}{ Within kingdom } & Protista & $(2 / 3)$ & $25.8 \sim 86.9$ & 62.9 \\
& Animalia & $(5 / 32)$ & $0 \sim 48.2$ & 21.0 \\
\multirow{2}{*}{ Within phylum } & Platyhelminthes & $(1 / 12)$ & $0 \sim 12.9$ & 7.5 \\
& Mollusca & $(1 / 4)$ & $2.0 \sim 11.1$ & 6.1 \\
& Arthropoda & $(2 / 3)$ & $1.8 \sim 44.4$ & 29.7 \\
& Echinodermata & $(1 / 1)$ & - & - \\
& Chordata & $(3 / 12)$ & 0 & $\sim 17.6$ \\
\hline \multirow{2}{*}{ Between kingdoms } & Protista - Animalia & $59.9 \sim 85.1$ & 67.9 \\
& Invertebrata (4 phyla) & $15.1 \sim 40.0$ & 26.8 \\
& Invertebrata (4 phyla) - Chordata & $14.1 \sim 48.2$ & 26.1 \\
\hline
\end{tabular}

scribed spacers evidently undergo rapid phylogenetic change, including insertions and deletions.

The homology in the conserved tracts and their occurrence in the same linear order in the ITS 2 of Xenopus and Rana (Fig. 4B) indicate that these tracts are indeed the unchanged remnants of common ancestral ITS sequences, as proposed by Furlong and Maden (1983). The considerable interspecific and intergeneric differences in spacing between some of the conserved tracts (Fig. 4B) may indicate a history of insertions and / or deletions and

Fig. 6. A phylogenetic tree constructed by the NJ method based on the nucleotide sequence divergences of the 5.8S rRNA gene among 35 species belonging to two kingdoms. The 5.8S rRNA gene sequences used in the phylogenetic analyses are from the following 35 species: Giardia intestinalis (Protista; X05396; Boothroyd et al., 1987), Tetrahymena thermophila (Protista; X54512; Engberg and Nielsen, 1990), Nyctotherus cordiformis (Protista; AJ009574; van Hoek et al., unpublished), Poracanthium furcatum (Digenea; AJ241791; Jousson et al., 1999), Ixodes scapularis (black-legged tick; L22276; Wesson et al., 1993), Bombyx mori (domestic silkworm; M36302; Fujiwara et al., 1987), Samia cynthia (ailanthus silkmoth; M10367; Feng et al., 1982), Lytechinus variegatus (green urchin; X00350; Hindenach and Stafford, 1984), Oncomelania hupensis (Mollusca; U93226; Lo, unpublished), Arianta arbustorum arbustorum (Mollusca; AF124052; Lo, unpublished), Arion rufus (Mollusca; X00131; Ursi et al., 1983), Stagnicola caperata (Mollusca; AF013140; Remigio and Blair, 1997), Poracanthium furcatum (Digenea; AJ241791; Jousson et al., 1999), Nicolla elongata (Digenia; AJ241792; Jousson et al., 1999), Cainocreadium labracis (Digenia; AJ241795; Jousson et al., 1999), Pseudopycnadena fishtali (Digenia; AJ241798; Jousson et al., 1999), Gaevskajatrema perezi (Digenia; AJ241800; Jousson et al., 1999), Macvicaria crassigula (Digenia; AJ241803; Jousson et al., 1999), Pachycreadium carnosum (Digenia; AJ241799; Jousson et al., 1999), Macvicaria alacris (Digenia; AJ241801; Jousson et al., 1999), Schistosoma mattheei (Digenia; Z2171; Kane and Rollinson, 1994), Plagiorchis vespertilionis (Digenia; AF151949; Tkach et al., 2000), Echinostoma trivolvis (Digenia; AF067852; Sorensen et al., 1998), Plagiorchis elegans (Digenia; AF151952; Tkach et al., 2000), Petromyzon marinus (sea lamprey; AF061798; Mallatt and Sullivan, 1998), Misgurnus fossilis (loach; M28025; Kupriyanova et al., 1984), Cyprinus carpio (carp; U87963; Vera et al., 1997), Xenopus laevis (African clawed frog; K01376; Ford and Mathieson, 1978), Xenopus borealis (Kenyan clawed frog; K01375; Ford and Mathieson, 1978), Rana nigromaculata (Japanese pond frog; AB099628; present study), Hydrolagus colliei (spotted ratfish; AF061799; Mallatt and Sullivan, 1998), Oncorhynchus keta (salmon; D45855; Naganuma et al., unpublished), Oncorhynchus mykiss (rainbow trout; V01346; Nazar and Roy, 1978), Mus musculus (house mouse; K01365; Goldman et al., 1983), Rattus norvegicus (rat; V01270; Chan et al., 1984) and Homo sapiens (human; U13369; Nazar et al., 1976). Numbers on the tree represent local bootstrap values (above 600) from 1,000 replicates. The scale bar represents branch length in terms of nucleotide substitutions per site. 
multiple changes in the intervening divergent regions.

In summary, the sequence contents of the divergent regions may have undergone extensive changes through the cumulative effects of many individual occurrences, including insertions, deletions, and point mutations.

The results of this study supported the following conclusions: 1) the rate of substitutions for the ITS regions was high (Li et al., 1985; Gillespie, 1986), thus making it difficult to compare sequences between Xenopus and Rana; 2) the short tracts in the ITS regions were strictly conserved between the two Xenopus species, and there were corresponding sequences for Rana. These results suggest that the conserved short tracts may be probably related to some important function such as the processing, although further examinations will be necessary for elucidating the function of these short tracts.

The coding regions. A comparison of the nucleotide sequences of the coding regions among Rana, human, and the two species of Xenopus revealed the following: (1) the $18 \mathrm{~S}$ and $5.8 \mathrm{~S}$ rRNA gene sequences were highly conserved among these taxa. (2) the regions corresponding to the stem and loop of the secondary structure of the $28 \mathrm{~S}$ rRNA gene were conserved between Xenopus and Rana, and the rate of substitutions for the loop was higher than that for the stem. (3) The human loop regions had large insertions not seen in amphibians. Figure 3 summarizes the differences among the four 28S rRNA gene sequences and the distribution of these differences between the conserved and variable regions. According to the known data on the two Xenopus species, that overall rate of divergence in the variable regions can be estimated to have been at least 20 -fold more rapid than that in the core regions (Ajuh et al., 1991). V8 corresponds to the 'double hairpin' seen by electron microscopy (Wellauer and Dawid, 1973; Wellauer et al., 1974; Wakeman and Maden, 1989). The variable regions, V2a, V5 and V8, of human are much longer than those in Rana and Xenopus due to large insertion sequences. By contrast, there is almost no length difference in these regions among frogs. The cumulative effects of insertions and deletions of sequence blocks in the variable regions could eventually generate a major length difference in the loop region of the gene found between Xenopus/Rana and human. Such length variation will make difficult to compare the nucleotide sequence between taxa. Thus, the variable regions in $28 \mathrm{~S}$ rRNA gene are thought to be most informative for elucidating phylogenetic relationships among anuran families.

Phylogenetic utility of $28 S$ and 5.8S rRNA gene sequences. Sequence studies of the rRNA genes from the conserved regions to the rapidly evolving regions, the so-called divergent domains or expansion segments, have proven useful for investigating the evolutionary diver- gences that have occurred over the evolution of the metazoans (Hillis et al., 1996). The more conserved regions have been useful for examining relationships among major phyla (Hillis et al., 1996). The relatively variable regions within the rRNA genes make them useful for examining relationships within more closely related groups, such as various groups of vertebrates (Larson and Wilson, 1989; Hillis et al., 1991, 1993, 1996). The ITS regions are useful for examining relationships among closely related species.

The 28S rRNA gene contains regions with both rapid and slow nucleotide substitution rates, hence gene sequences of $28 \mathrm{~S}$ rRNA have been frequently used in phylogenetic analyses for various organisms, from deep to recently diverged taxa. The present phylogenetic tree constructed from 28S rRNA gene sequences closely corresponded with the generally accepted phylogenetic relationship of these two frog groups (e.g. Kobel et al., 1998). This result may imply that this gene is also suitable for elucidating the phylogenetic relationships among extensive anuran families, including the primitive Pipidae and more evolved Ranidae. The present result also suggested that the substitution rate of the 28S rRNA gene was constant in the Rana and Xenopus species. The constant rate allowed us to estimate the divergence times of the frogs using a molecular clock of the gene sequence. Thus, we estimated the per-site number of nucleotide changes on each branch in the linearized tree by using the LS method (Fig. 5). Based on the values and a diverged time, $360 \mathrm{Myr}$, between amphibians and other tetrapods (see Kumar and Hedges, 1998), the nucleotide substitution rate, $0.117 \%$ per $10 \mathrm{Myr}$, was estimated. This scale indicated that the two Xenopus species diverged about 26 Myr ago, and that Rana and Xenopus diverged about 214 Myr ago. According to mitochondrial rRNA gene sequence data collected by Kobel et al. (1998), the two Xenopus species diverged about $30 \mathrm{Myr}$ ago (close to our estimate of $26 \mathrm{Myr}$ ), while the two anuran families diverged about 130 Myr ago (much smaller than our estimate of $214 \mathrm{Myr}$ ). In the mtDNA data, multiple substitutions may have occurred between the two families (Sumida et al., unpublished), resulting in the estimation of a shorter divergence time. The constant rate between two families confirms that multiple substitutions may be excluded from the present data based on the nuclear rRNA gene. For this reason, we conclude that our present estimate for the divergence time may be reasonable.

The 5.8S rRNA gene region evolves relatively slowly, at a speed similar to that of the other coding regions, but its location within the ITS has precluded its use as anything but an alignment tool. Recently, however, this region of DNA was shown to contain considerable phylogenetic information, particularly with respect to deep basal branches (Cullings and Vogler, 1998). In the present 
phylogenetic tree constructed by the NJ method based on the 5.8S rRNA gene sequence data, the ingroup Animalia, in which the monophyly was supported in $60 \%$ of 1000 bootstrap iterations, were grossly divided into several clades, including five phyla. The phylum Chordata, in which monophyly was supported in $61 \%$ of 1000 bootstrap iterations, did not show any distinct divergences among fishes, frogs, and mammals. While the 5.8S rRNA gene sequence data may be helpful for examining the monophyly of each phylum, the sequence data (162 bp) is short for a tree that includes so many taxa, limiting its utility for elucidating relationships among phyla or within phylum.

The authors are especially indebted to the Emeritus Professor M. Nishioka of Hiroshima University for her encouragement during the course of this work. Sincere thanks are also extended to Prof. M. Hasegawa, Institute of Statistical Mathematics, for his kind and valuable advice for our data analyses. This work was supported by a Grant-in-Aid for Scientific Research (C) (No. 13839012) from the Ministry of Education, Culture, Sports, Science and Technology, Japan (to M. Sumida). The authors thank the Cryogenic Center of Hiroshima University for supplying liquid nitrogen for DNA extraction.

\section{REFERENCES}

Ajuh, P. M., Heeney, P. A., and Maden, B. E. H. ( 1991) Xenopus borealis and Xenopus laevis 28S ribosomal DNA and the complete $40 \mathrm{~S}$ ribosomal precursor RNA coding units of both species. Proc. R. Soc. Lond. B 245, 65-71.

Boothroyd, J. C., Wang, A., Campbell, D. A., and Wang, C. C. (1987) An unusually compact ribosomal DNA repeat in the protozoan Giardia lamblia. Nucl. Acids Res. 15, 40654084 .

Chan, Y. L., Gutell, R., Noller, H. F., and Wool, I. G. (1984) The nucleotide sequence of a rat $18 \mathrm{~S}$ ribosomal ribonucleic acid gene and a proposal for the secondary structure of $18 \mathrm{~S}$ ribosomal ribonucleic acid. J. Biol. Chem. 259, 224-230.

Cullings, K. W., and Vogler, D. R. (1998) A 5.8S nuclear ribosomal RNA gene sequence database: applications to ecology and evolution. Mol. Ecol. 7, 919-923.

Davis, L. G., Dibner, M. D., and Battey, J. F. (1986) Basic Methods in Molecular Biology. Elsevier Science Publ., New York.

Engberg, J., and Nielsen, H. (1990) Complete sequence of the extrachromosomal rDNA molecule from the ciliate Tetrahymena thermophila strain B1868VII. Nucl. Acids Res. 18, 6915-6919.

Felsenstein, J. (1993) PHYLIP (Phylogeny Inference Package) Version 3.5c. Univ. Washington Press, Seattle.

Feng, Y. X., Krupp, G., and Gross, H. J. (1982) The nucleotide sequence of 5.8S rRNA from the posterior silk gland of the silkworm Philosamia cynthia ricini. Nucl. Acids Res. 10, 6383-6387.

Ford, P. J., and Mathieson, T. (1978) The nucleotide sequences of 5.8S ribosomal RNA from Xenopus laevis and Xenopus borealis. Eur. J. Biochem. 87, 199-214.

Fujiwara, H., Maekawa, H., Ninaki, O., Takada, N., Miyajima, N., and Ishikawa, H. (1987) Comparative studies on the rDNA of the silkworm, Bombyx mori and its presumed ancestor. Comp. Biochem. Physiol. 88, 761-766.
Furlong, J. C., and Maden, B. E. H. (1983) Patterns of major divergence between the internal transcribed spacers of ribosomal DNA in Xenopus borealis and Xenopus laevis, and of minimal divergence within ribosomal coding regions. EMBO J. 2, 443-448.

Furlong, J. C., Forbes, J., Robertson, M., Maden, B. E. H. (1983) The external transcribed spacer and preceding region of Xenopus borealis rDNA: comparison with the corresponding region of Xenopus laevis rDNA. Nucl. Acids Res. 11, 81838196.

Gerbi, S. A. (1985) Evolution of ribosomal DNA. In: Molecular Evolutionary Genetics (eds.: R. J. MacIntyre), pp.419-517. Plenum, New York.

Gerbi, S. A. (1986) The evolution of eukaryotic ribosomal DNA. BioSystems 19, 247-258.

Gillespie, J. H. (1986) Rates of molecular evolution. Annu. Rev. Ecol. Syst. 17, 637-665.

Goldman, W. E., Goldberg, G., Bowman, L. H., Steinmetz, D., and Schlessinger, D. (1983) Mouse rDNA: sequences and evolutionary analysis of spacer and mature RNA regions. Mol. Cell Biol. 3, 1488-1500.

Gonzalez,I.L., and Sylvester, J.E. (1995) Complete sequence of the $43-\mathrm{kb}$ human ribosomal DNA repeat: analysis of the intergenic spacer. Genomics 27, 320-328.

Graf, J-D., and Kobel, H. R. (1991) Genetics of Xenopus laevis. In: Methods in Cell Biology (eds.: B. K. Kay, and H. B. Peng), vol. 36, pp.19-34. Academic Press, New York.

Hillis, D. M., Dixon, M. T., and Ammerman, L. K. (1991) The relationships of the coelacanth Latimeria chalumnae: Evidence from sequences of vertebrate $28 \mathrm{~S}$ ribosomal RNA genes. Environ. Biol. Fishes 32, 119-130.

Hillis, D. M., Ammerman, L. K., Dixon, M. T., and de Sá, R. O. (1993) Ribosomal DNA and the phylogeny of frogs. Herpetol. Monog. 7, 118-131.

Hillis, D. M., Mable, B. K., Larson, A., Davis, S. K., and Zimmer, E. A. (1996) Nucleic acids IV: Sequencing and cloning. In: Molecular Systematics (eds.: D. M. Hillis, C. Moritz, and B. K. Mable), pp. 321-381. Sinauer, Sunderland, MA.

Hindenach, B. R., and Stafford, D. W. (1984) Nucleotide sequence of the 18S-26S rRNA intergene region of the sea urchin. Nucl. Acids Res. 12, 1737-1747.

Hughes, M. K., and Hughes, E. (1993) Evolution of duplicate genes in a tetraploid animal, Xenopus laevis. Mol. Boil. Evol. 10, 1360-1369.

Jousson, O., Bartoli, P., and Pawlowski, J. (1999) Molecular identification of developmental stages in Opecoelidae (Digenea). Int. J. Parasitol. 29, 1853-1858.

Kane, R. A., and Rollinson, D. (1994) Repetitive sequences in the ribosomal DNA internal transcribed spacer of Schistosoma haematobium, Schistosoma intercalatum and Schistosoma mattheei. Mol. Biochem. Parasitol. 63, 153-156.

Kimura, M. (1980) A simple method for estimating evolutionary rates of base substitutions through comparative studies of nucleotide sequences. J. Mol. Evol. 16, 111-120.

Kobel, H. R., Barandun, B., and Thiebaud, Ch. H. (1998) Mitochondrial rDNA phylogeny in Xenopus. Herpet. J. 8, 13-17.

Kumar, S., and Hedges, B. (1998) A molecular timescale for vertebrate evolution. Nature 392, 917-920.

Kumar, S., Tamura, K., Jakobsen, I. B., and Nei, M. (2001) MEGA2: Molecular Evolutionary Genetics Analysis Software. Bioinformatics 17, 1244-1245.

Kupriyanova, N. S., Serenkova, T. I., Mazo, A. M., and Timofeeva, M. Y. (1984) Investigation of a cloned portion of the ribosomal operon coding the 5.8S rRNA of the loach Misgurnus fossilis. Mol. Biol. 18, 1126-1134. 
Larson, A., and Wilson, A. C. (1989) Patterns of ribosomal RNA evolution in salamanders. Mol. Biol. Evol. 6, 131-154.

Li, W.-H., Luo, C. C., and Wu, C. I. (1985) Evolution of DNA sequences. In: Molecular Evolutionary Genetics (eds.: R. J. MacIntyre), pp.1-94. Plenum, New York.

Lipps, H. J., and Steinbruck, G. (1982) Free genes for rRNAs in the macronuclear genome of the ciliate Stylonychia mytillis. Chromosoma 69, 21-26.

Mallatt, J., and Sullivan, J. (1998) 28S and 18S rDNA sequences support the monophyly of lampreys and hagfishes. Mol. Biol. Evol. 15, 1706-1718.

Nazar, R. N., Sitz, T. O., and Busch, H. (1976) Sequence homologies in mammalian 5.8S ribosomal RNA. Biochemistry 15, 505-508.

Nazar, R. N., and Roy, K. L. (1978) Nucleotide sequence of rainbow trout (Salmo gairdneri) ribosomal 5.8S ribonucleic acid. J. Biol. Chem. 253, 395-399.

Nei, M. (1987) Molecular Evolutionary Genetics. Columbia Univ., New York.

Nei, M., and Kumar, S. (2000) Molecular Evolution and Phylogenetics. Oxford Univ., New York.

Remigio, E. A., and Blair, D. (1997) Relationships among problematic North American stagnicoline snails (Pulmonata:Lymnaeidae) reinvestigated using nuclear ribosomal DNA internal transcribed spacer sequences. Can. J. Zool. 75, 1540-1545.

Rozas, J., and Rozas, R. (1999) DnaSP version 3: an integrated program for molecular population genetics and molecular evolution analysis. Bioinformatics 15, 174-175.

Saitou, N., and Nei, M. (1987) The neighbor-joining method: A new method for reconstructing phylogenetic trees. Mol. Biol. Evol. 4, 406-425.

Sorensen, R. E., Curtis, J., and Minchella, D. J. (1998) Intraspecific variation in the rDNA ITS loci of 37-collar-spined echinostomes from North America: implications for sequencebased diagnoses and phylogenetics. J. Parasitol. In press.

Stumph, W. E., Wu, J. R., and Bonner, J. (1979) Determination of the size of rat ribosomal DNA repeating units by electron microscopy. Biochemistry 18, 2864-2871.

Sumida, M. (1997) Inheritance of mitochondrial DNAs and allzymes in the female hybrid lineages of two Japanese pond frog species. Zool. Sci. 14, 277-286.

Sumida, M., and Nishioka, M. (2000) Sex-linked genes and link- age maps in amphibians. Comp. Biochem. Physiol. B 126, 257-270.

Sumida, M., Kanamori, Y., Kaneda, H., Kato, Y., Nishioka, M., Hasegawa, M., and Yonekawa, H. (2001) Complete nucleotide sequence and gene rearrangement of the mitochondrial genome of the Japanese pond frog Rana nigromaculata. Genes Genet. Syst. 76, 311-325.

Tajima, F. (1993) Simple method for testing the molecular evolutionary clock hypothesis. Genetics 135, 599-607.

Thompson, J. D., Higgins, D. G., and Gibson, T. J. (1994) CLUSTAL W: improving the sensitivity of progressive multiple sequence alignment through sequence weighting, position-specific gap penalties and weight matrix choice. Nucl. Acids Res. 22, 4673-4680.

Tkach, V. V., Pawlowski, J., and Sharpilo, V. P. (2000) Molecular and morphological differentiation between species of the Plagiorchis vespertilionis group (Digenea, Plagiorchiidae) occurring in European bats, with a re-description of $P$. vespertilionis (Muller, 1780). Syst. Parasitol. 47, 9-22.

Ursi, D., Vandenberghe, A., and De Wachter, R. (1983) Nucleotide sequences of the 5.8S rRNAs of a mollusc and a porifer, and considerations regarding the secondary structure of 5.8S rRNA and its interactions with 28S rRNA. Nucl. Acids Res. 11, 8111-8121.

Vera, M. I., Rios, H. M., de la Fuente, E., Figueroa, J., and Krauskopf, M. (1997) Seasonal acclimatization of the carp involves differential expression of 5.8S ribosomal RNA in pituitary cells. Comp. Biochem. Physiol. B 118, 777-781.

Wakeman, J. A., and Maden, B. E. H. (1989) 28S ribosomal RNA in vertebrates: locations of large-scale features revealed by electron microscopy in relation to other features of the sequences. Biochem. J. 258, 49-56.

Wellauer, P. K., and Dawid, I. B. (1973) Secondary structure maps of RNA: processing of HeLa ribosomal RNA. Proc. Natl. Acad. Sci. USA 70, 2827-2831.

Wellauer, P. K., Dawid, I. B., Kelly, D. E., and Perry, R. P. (1974) Secondary structure maps of ribosomal RNA: processing of mouse L-cell ribosomal RNA and variations in the processing pathway. J. Mol. Biol. 89, 397-407.

Wesson, D. M., McLain, D. K., Oliver, J. H., Piesman, J., and Collins, F. H. (1993) Investigation of the validity of species status of Ixodes dammini (Acari: Ixodidae) using rDNA. Proc. Natl. Acad. Sci. USA 90, 10221-10225. 